\title{
Congenital pain asymbolia and auditory imperception
}

\author{
B. O. OSUNTOKUN, E. L. ODEKU, AND L. LUZZATO \\ From the Departments of Psychiatry and Neurology, Surgery (Neurosurgery Unit), \\ and Pathology (Sub-department of Haematology), \\ University College Hospital, Ibadan, Nigeria
}

Congenital indifference to pain (pain asymbolia) is a rare condition. Since Dearborn in 1931 described the first case, 51 cases have been reported in the English literature. Congenital auditory imperception as an isolated defect is equally uncommon. It is perhaps the least uncommon of the various types of congenital aphasia. We have recently studied a family in which two siblings showed an association of pain asymbolia and auditory imperceptionan association that has not been reported in the English literature as far as we know, although Ford and Wilkins (1938) reported stuttering and specific reading disability associated with pain asymbolia. Boyd and Nie (1949) suggested that there is no specific 'underlying defect in pain asymbolia, but that it is rather an aphasia-like disturbance and hence may be related to the congenital aphasia and perhaps be dependent upon lack of established cerebral dominance'. Alajouanine and Lhermitte (1965) believed that the congenital aphasia is characterized by a defect in language elaboration at the origin of which there may or may not be a cerebral lesion. Our findings regarding the association of pain asymbolia and auditory imperception tend to support the view of Boyd and Nie.

\section{CASE REPORTS}

CASE 1 B.D. (U.C.H. No. 156097), a 5-year-old boy of Yoruba parentage, was first seen in April 1966. His parents said he did not hear and talk properly. What he said was an unintelligible semblance of normal speech. He understood sign language very well. He would turn to the source or direction of a sound or voice, but appeared not to comprehend spoken words or commands unless backed by appropriate gesticulations. He was however capable of utilizing a limited vocabulary in Yoruba language - thus he could say properly and in appropriate circumstances 'baba', 'mama', 'odabo', 'kabo': Yoruba words for 'father', 'mother', 'bye-bye', and 'welcome'. He rarely cried, but shed tears normally when he did and appeared incapable of being easily hurt, his parents describing him as 'a very strong boy'. He was very prone to ulcers on his feet. His toilet habits were said to be normal. There was no history of excessive or diminished sweating or of measles infection in early childhood. He had suffered from discharge in the right ear for six months. He had been a normal boy socially and showed no trace of psychotic behaviour except that he often reacted violently when angry or annoyed. The mother was well throughout pregnancy and gave no history of rubella, mumps, or measles. Delivery and the developmental history of the propositus were normal.

The propositus is the third child of his mother (who was 25 years old when he was born) (see Fig. 1). A half-sister was similarly affected. His mother and the half-sister's mother are unrelated. There was no family history of left-handedness, skeletal deformities, premature greying of hairs, white forelock, or goitre.

Examination showed a healthy-looking right-handed boy, the height and weight being $96.5 \mathrm{~cm}$ and $13.5 \mathrm{~kg}$ respectively. The skull was normal in shape and the circumference of the head was 21.5 in. The face was also normal and the eyes were without hypertelorism, blue sclerotics, or epicanthic folds. The upper central incisors were peg-shaped, resembling Hutchinson's teeth in congenital syphilis, but he had no other syphilitic stigmata of congenital syphilis. He had numerous scars on his feet and leg, but these were not remarkable in a Yoruba boy, who habitually walked bare-footed. The skin of the axillae showed the presence of sweat.

Neurological examination showed normal sensorium. The fundi, corneal reflexes, and the other functions of the cranial nerves were found to be normal. There was no detectable abnormality in the motor system, the muscles, the gait, and coordination being normal. Tendon and superficial reflexes were normal. In the sensory system light touch was normal. Communication difficulty made temperature sense impossible to test. His reaction to noxious stimuli was, however, odd. He knew when he was being pricked by a pin, for he could tell the difference by gesture between the sharp and blunt ends. He showed no withdrawal response, evasive or preventive motor reactions, and no facial expression of pain to pin-prick venepuncture, intense pressure on the achilles tendon, or to his skin being transfixed with a needlewhich he seemed to enjoy very much. He invited the examiner to repeat the tests while he remained all smiles. There was no alteration in the pulse, blood pressure, respiratory rate, and pupillary sizes to noxious stimuli.

The speech was abnormal. He undoubtedly heard voices but did not appreciate the symbolic significance of most spoken words. Separated from a source of sound by 
a screen or a door he would correctly localize the source by going round the screen or through the doorway. A similar finding was obtained using the Barany's sound box. He appeared to be able to hear the high-pitched ticking of an Omega wrist watch. He understood sign language very well. $\mathrm{He}$ exhibited idioglossia-strange words most unintelligibly strung together, but with occasional recognizable normal words being produced. His vocabulary also improved in hospital and with deliberate efforts to teach him. He showed no signs of apraxia, and could dress himself and find his way around the hospital. Hie could also copy simple figures reasonably well.

There was no abnormality in the cardiovascular system. The blood pressure was $90 / 70 \mathrm{~mm} \mathrm{Hg}$ and the pulse $90 / \mathrm{min}$ with no evidence of postural hypotension. Four-hourly recording of blood pressure, pulse, temperature, and respiration rate over a period of four weeks showed no abnormality. The chest and abdomen were normal.

Mental assessment Bedside testing showed a boy of average intelligence. A modification of the performance tests of intellectual process suggested for the Nutrition survey of Nigeria in 1965 was used (U.S. Office of International Research, 1966). Psychological tests like the Cattell infantile intelligence scale are not suitable for Yoruba children as the background culture is different. His parents also said he was mentally normal.

Investigations Haemoglobin was $10.7 \mathrm{~g} / 100 \mathrm{ml}$. blood, M.C.H.C. was 32, white blood cell count was $12,000 \mathrm{cu}$. $\mathrm{mm}$ with normal differential. The haemoglobin electrophoretic pattern was AC. Thyroid function tests were normal: plasma bound iodine was $6.8 \mu \mathrm{g} \%$, red blood cell uptake of ${ }^{131}$ triodothyronine was $11 \cdot 2 / 100$ $\mathrm{ml}$. haematocrit (12-18\% range of normal); plasma cholesterol was $138 \%$. Total serum protein was $7.6 \mathrm{~g} \mathrm{\%}$ (serum albumin was $3.4 \mathrm{~g} \%$ ) with normal electrophoretic strip. Serum electrolytes and blood urea were normal. Serological test (Kahn test) for syphilis was negative in the blood and cerebrospinal fluid; the latter showed a protein content of $25 \mathrm{mg} \%$, no cells, and the fluid pressure was normal (110 $\mathrm{mm}$ cerebrospinal fluid). Biopsy of the skin, which was carried out without local anaesthesia soon after admission into the hospital, showed normal fine nerve fibres present in the dermis on histological examination. A section fixed in formolsucrose for neurite impregnation with silver showed no abnormality. Paper chromatography of urine showed no abnormal aminoacids. Caloric tests showed normal vestibular function. Otoscopy showed right chronic otitis media with central perforation. Unfortunately, the child was too uncooperative for audiometry. Intradermal Mecholyl $(0.1 \mathrm{ml}$.$) produced profuse sweating, and$ subcutaneous Mecholyl $(3 \mathrm{mg})$ produced sweating and tearing. Miosis was produced when Mecholyl was instilled into the conjunctival sacs. Plain radiographs of chest, skull, and sinuses were normal, as were tomographs of petrous bone. Cisternal pneumoencephalography showed no abnormality. Bell stimuli produced Kcomplexes and spindles in the electroencephalogram obtained during barbiturate-induced sleep.

Progress The patient was in hospital for eight weeks, during which news got around of the 'wonder boy' who를 could not feel pain. Subsequently about four weeks after hospitalization some laboratory technicians surrep titiously paid him several visits, transfixing him with pins. and needles and watching with awe how much he enjoyede it. He appeared however to discover that he was being regarded as a 'freak' and developed the greatest dislike of pins and neetles. He would fly into an uncontrollable rage and temper tantrums at the slightest exhibition of pin or needle, but would allow himself with much plea. sure to be subjected to other forms of noxious stimul like pressure on the tendon achilles and hot water at: $75^{\circ} \mathrm{C}$.

When seen and re-evaluated in his home eight monthe after discharge from the hospital, he showed completeindifference to pin prick and venepuncture just as duringe his first visit to the hospital. His vocabulary had increased and his speech was slightly more intelligible.

CASE 2 O.D., a half-sister of the boy (Case 1) was 4 years old when she was brought along with him to the? neurology clinic with the same complaints as described $\vec{\omega}$ above for the boy. She showed similar abnormal speector and stoical indifference to pain. Pregnancy and deliverys were normal, and development was normal except fo 0 disturbance of speech and reaction to pain. There was now history of otitis media. She shed tears normally on tbe few occasions she cried. She was the third child of mother who was about 28 years old when the proposidis was born (see Fig. 1).

Examination showed a bright-looking right-handedP child with no neurological or physical deficit except $t$ her reaction to noxious stimuli and in understandingco spoken words as described above for her half-brother.o no addition, however, she had blue sclerotics. Her blo d- $-\overrightarrow{0}$ pressure was $95 / 70 \mathrm{~mm} \mathrm{Hg}$ and pulse rate was $90 / \mathrm{m}$. with no evidence of postural hypotension. Sweat could $\vec{b} e^{\infty}$ felt in the axilla, and sweating and tearing were induced by subcutaneous Mecholyl.

Haematological indices were normal: haemoglobin was $11.7 \mathrm{~g} \%$, packed cell volume was $38 \%$, M.C.H.C. was 31 , white cell count was $10,000 / \mathrm{cu}$. mm with norma differential count, and the haemoglobin electrophoretic pattern was AA. Plasma bound iodine was $4.4 \mu \mathrm{g} / 100 \overrightarrow{\mathrm{E}}$ ml., red blood cell uptake of ${ }^{131}$ triodothyronine was $13 / 100$; haematocrit and serum cholesterol was $114 \mathrm{mg} \%$; Total serum protein was $8.3 \mathrm{~g} \%$ with a serum albumino of $3.6 \mathrm{~g} \%$ and normal electrophoretic strip. Histology of skin sections showed normal fine nerve endings. Plain radiographs of skull, sinuses, and chest, and tomograms of the petrous temporal bone revealed no abnormality. Paper chromatography of urine showed no abnormat. aminoacids. Otoscopy showed no abnormality. Calorico tests for vestibular functions were normal. It is regretted 3 that the parents did not allow her to be admitted intoo hospital for further investigation.

FAMILY STUDY The family was visited and examined in the village where the members lived. Blood was collected for determination of certain genetic markers: $\mathrm{ABO}_{\text {, }}$ MNSs, and Rh groups, haemoglobin electrophoretic pattern, glucose 6 phosphate dehydrogenase (G-6-P-D), 


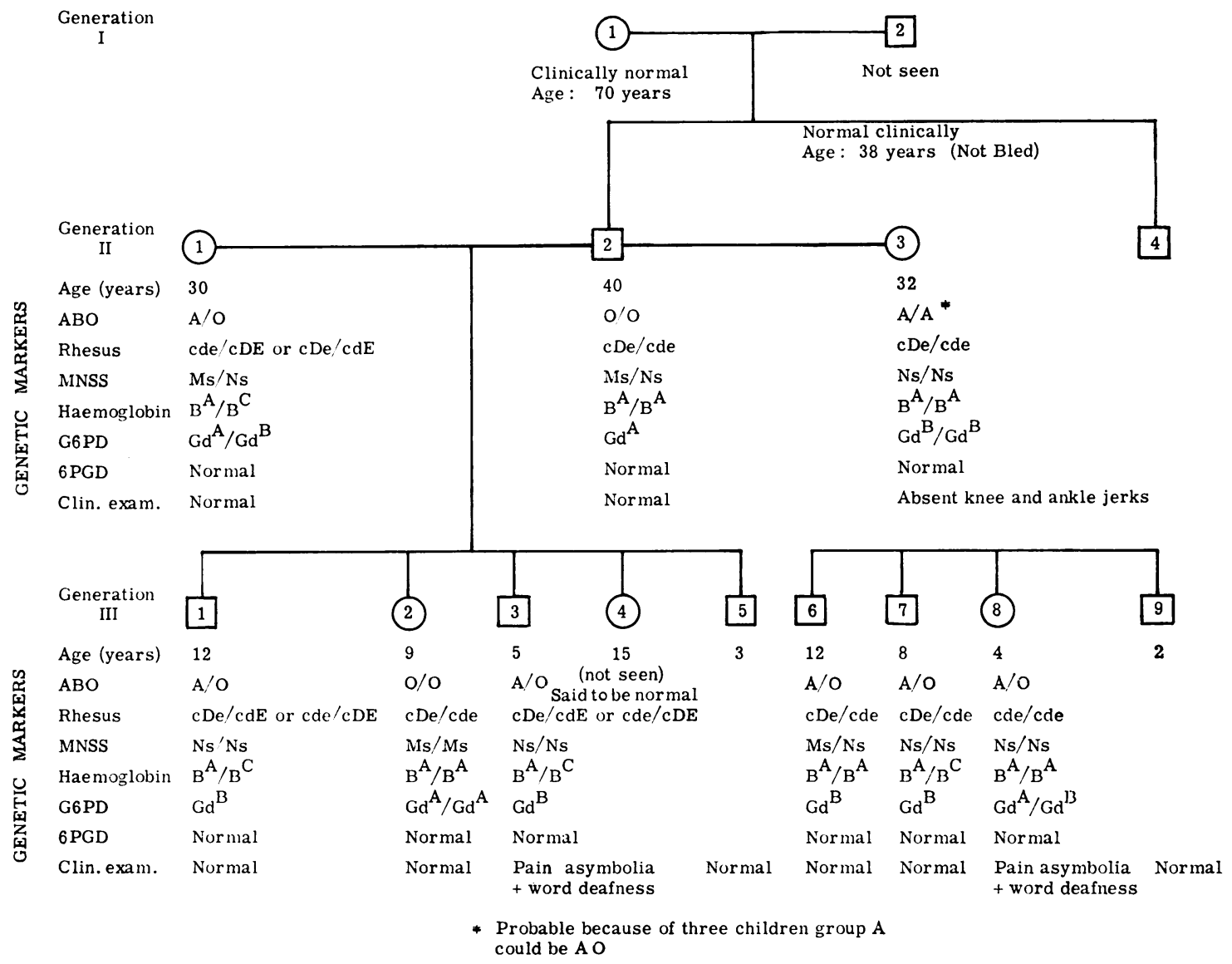

FIG. 1. Family Study

and 6-phosphogluconate dehydrogenase deficiency (6-PGD). ABO, Rhesus, and MNSs groups were determined by standard tube technique with potent antisera. Haemoglobin type was determined by starch-gel electrophoresis in tris-borate buffer at $p \mathbf{H} 8.6$. Glucose6-phosphate dehydrogenase electrophoretic variants were examined as previously described (Luzzatto and Allan, 1965). 6-phospho-gluconic dehydrogenase was analysed by the same technique, except that 6-phosphogluconate replaced glucose-6-phosphate in the staining of the gel. The results are shown in Figure 1.

\section{DISCUSSION}

There have been several reviews of the literature on pain asymbolia or congenital indifference to pain (Ford and Wilkins, 1938; Critchley, 1956; Fanconi and Ferrazzini, 1957; Ogden, Robert, and Car7 michael, 1959; Baxter and Olszewski, 1960). Most cases have occurred in children, although a number of cases have been reported in adults (Dearborn, 1931 ; Kunkle and Chapman, 1942; Magee, Schneider, and Rosenzweig, 1961). Ogden et al. (1959) enumerated criteria to establish the diagnosis and to differentiate it from sensory neuropathies and spinal cord disorders such as syringomyelia and tumours. Pinsky and D́iGeorge (1966) discussed lucidly the differential diagnosis of congenital or hereditary causes of insensitivity to pain. These authors stressed that mental subnormality and familial dysautonomia should be excluded. We have also observed some partial but reversible insensitivity to pain in patients with severe proteincalorie deficiency (Kwashiorkor) probably due to the apathy and mental retardation characteristic of 
the clinical syndrome. The diagnosis of congenital indifference to pain should be made only in the absence of demonstrable lesion in the peripheral nerves, spinal cord, thalamus, and the cerebral cortex. Exhaustive post-mortem studies in two cases showed no significant evidence of any structural lesion in the central nervous system except for an equivocal diminution in the number of myelinated fibres in the subcallosal fasciculus in one case. The physiological significance of this is unknown (Magee, 1963; Baxter and Olszewski, 1960). Our cases satisfy the criteria of Ogden et al. (1959). The other conditions that may simulate congenital indifference to pain, such as congenital sensory neuropathy, hereditary sensory radicular neuropathy, familial sensory neuropathy with anhidrosis, and familial dysautonomia (Pinsky and D́iGeorge, 1966) were also excluded. It should be stressed, however, that in congenital indifference to pain, only the affective component of the response to painful stimuli is absent.

It has been suggested that indifference to pain may wax and wane and tend to subside as the patient becomes older, partly because of regression of the disorder and partly because other qualities of sensation and intellectual functions take over as substitutes (Magee et al., 1961). A mentally normal child may learn to recognize those things which are injurious and thereby avoid damage to himself. Our patient, fully capable of learning, objected to being treated as a circus animal by laboratory technicians, especially when confronted with a pin or needle, but showed complete indifference to other forms of noxious stimulation. This suggests that such subsidence or disappearance of congenital indifference to pain is the result of an avoidance reflex to such conditioning stimuli as evoked either demonstrable trauma or disagreeable psychological effects. In the classical pattern of a conditioned reflex that is not reinforced, eight months later, our first patient had lost the avoidance response to pin prick that he acquired during his stay in the hospital. Bony changes, such as fractures, aseptic necrosis, osteomyelitis, and also neuropathic joints reported in the literature, were not seen in our cases (Westlake, 1952; Houwen, 1961 ; Silverman and Gilden, 1959, Gwinn, Barnes, Tucker, and Johnson, 1966).

The association of pain asymbolia with auditory imperception shown in the present report suggests that the site of the responsible lesion may be cortical or subcortical, involving the projection fibres to the dominant temporal lobe. Brain (1961) localizes pure word deafness to the auditory receptor area in the dominant hemisphere. In explaining the aphasia sometimes resulting from stereotactic operations on the globus pallidus or optic thalamus for the relief of Parkinsonism, Brain (1961) has suggested the possibility that the corpus striatum is more directly $\bar{Z}$ concerned in speech through its corticothalamic and $\stackrel{\mathbb{D}}{\subset}$ thalamo-cortical connexion. Although Schilder and Stengel (1931) described an acquired asymbolia for pain caused by a lesion in the posterior parietal $\widehat{0}$ region of the dominant hemisphere, the nature of $D$ the defect in congenital indifference to pain is unknown, despite post mortem studies on two cases $\frac{?}{\overrightarrow{0}}$. (Magee, 1963; Baxter and Olszewski, 1960). Swanson, Buchan, and Alvord (1965) report absence of small primary classical pain-temperature neurones in the spinal ganglia, dorsal roots, spinal $\vec{\sigma}$ cord, and medulla oblongata, and at all levels in the $\bar{\sigma}$ spinal cord the absence of Lissauer's tract-the $\frac{\bar{c}}{\sigma}$ myelinated tract just lateral to the entering posterior $\mathbb{\otimes}$ root which continues into the superficial dorsal grey horn. But the case they described, familial sensory neuropathy with anhidrosis, is different from congenital indifference to pain.

The neurophysiology of pain has recently been the subject of controversy (Gerard, 1960; Melzack and Wall, 1965). Although Critchley (1956) suggests that congenital indifference to pain may simply lie $\omega$ at one end of a pain spectrum, at the other end op $\omega$ which are patients who are constitutionally hypero if sensitive to pain, it is still possible that corticas integration of pain may be defective in those whe 응 appear stoical to pain. A patient after fronta $\vec{c}$ lobectomy still feels pain, but does not worry s $\$$ much about it-that is, the Sherringtonian concepe of pain as the sensory adjunct of an imperative. $\vec{\theta}$ protective reflex no longer applies to him. Morphine does not raise the threshold of pain receptors to peripheral stimulation but possibly acts at the cortical level: the message comes to the nervous system as before but no longer seems as important as formerly (Gerard, 1960). These suggest that the integrity of the cerebral cortex is necessary for the full appreciation of pain (British Medical Journal, 1961). There is, of course, a tremendous variability in the reaction of a given individual to a given painful stimulus. In the intense emotion of a battle the severely wounded soldier feels little pain, but in the calmer atmosphere of the hospital base he may require large doses of analgesics (Beecher, 1959). Pavlov's dogs, which received electric shocks, burns, or cuts followed consistently by the presentation of food, eventually responded to these stimuli as signals for food and failed to show even the 'tiniest and most subtle signs of pain' (Pavlov, 1928).

On the other hand, a lesion to account for congenital indifference to pain may be molecular or enzymatic, as has been postulated for congenital aphasia (Eisenson, 1963). Becak, Becak, and Schmidt in 1963 reported two siblings with con- 
genital insensitivity to pain who had an unusual substance in their urine and mosaic trisomy for a chromosome in the D (13-15) group. Late development of speech and poor articulation have been described in association with indifference to pain in familial dysautonomia (Riley-Day syndrome), a disorder believed to be due to abnormal metabolism of pressor amine precursors (Riley, 1949; Riley, 1957; Dancis and Smith, 1966; Smithells, 1967). This is tenable if the classical concepts of the neurophysio-pathology of pain are rejected. Melzack and Wall (1965) wrote that 'the concept of a pain centre in the brain is totally inadequate for the sequences of behaviour and experience. Indeed the concept is pure fiction unless virtually the whole brain is considered to be the pain centre because the thalamus, the limbic system, the hypothalamus, the brain stem reticular formation, the parietal cortex and the frontal cortex are all implicated in pain perception. Other brain areas are obviously involved in the emotional and motor features of the behaviour sequence. The idea of a terminal centre in the brain which is exclusively responsible for pain sensation and response therefore becomes meaningless.' The pain relieving effect of anterolateral cordotomy and thalamectomy does not mean that these areas carry a specific pain system. The lesions have multiple effects; they reduce the total number of responding neurones, change temporal and spatial relationships among all ascending systems, and affect the descending feedback that controls transmission from peripheral fibres to dorsal horn cells (Sweet, 1959).

The congenital or developmental aphasias are often of a non-organic nature and thought to be due to lag in the maturation of the part of the central nervous system which deals with the span of auditory attention and with language formulation (Sheridan, 1961). They are often associated with cerebral non-dominance, of which there was no evidence in our patients. We were careful to exclude high-tone deafness in these patients as this may mimic congenital auditory imperception very closely (Creak, 1932; Sheridan, 1961). Our patients, as in the cases cited by Allen (1952), could repeat certain simple words. They did not show any feature of childhood schizophrenia, or of infantile autism, two other conditions which may be confused with congenital auditory imperception or any of the various types of congenital aphasias (Sheridan, 1961; Eisenson, 1963). It is hopefully expected that our patients will improve in their acquisition of language - a not uncommon phenomenon in the congenital aphasias (Sheridan, 1961). There are those who regard developmental auditory imperception as psychogenic and who believe that imperception may follow infantile psychosis (Davis, 1957). Others think it arises as a congenital defect (Berg, 1961). We found no evidence of a psychogenic cause in our cases. We could not demonstrate by standard techniques and investigation any structural defect in one of our patients who was fully investigated.

GENETICS The familial incidence of congenital pain asymbolia or indifference to pain has been recorded by Magee et al. (1961), Silverman and Gilden(1959), and Houwen (1961). Pinsky and DiGeorge (1966) reported two siblings with familial sensory neuropathy and anhidrosis. Congenital sensory neuropathy, although sporadic may be transmitted by a dominant mode of inheritance (Ervin and Steinbach, 1960). Gillespie and Perucca (1960) suggested that congenital indifference to pain is probably recessively inherited. The study in respect of possible genetic markers and linkage in the family reported by us is largely negative. The fact that the two affected half-sibs had different mothers leads to the almost inescapable conclusion that they both inherited an abnormal gene from the father. Further, the different sex of the two propositi virtually rules out X-linkage. The pattern of inheritance is difficult to interpret beyond these two points. If the abnormal gene were dominant, it should have given some manifestations in the father; if it were recessive, we would have to make the supplementary assumption that both wives carried it-a very unlikely assumption in view of the great rarity of the condition. The only other alternative possibilities are the so-called 'incomplete penetrance' (of extreme degree since the father was completely unaffected!) or interaction with other gene(s) present in the propositi but not in their father. Linkage data obtained from this family are negative. Pain asymbolia does not appear to be closely linked to MSNs blood groups, since the two propositi inherited Ns from their father, but so did III-I and III-7 who were unaffected. Linkage to 6-P-G-D cannot be scored because there is no polymorphism in this family. Linkage to $\mathrm{ABO}$ blood groups and haemoglobin type cannot be scored because the father is homozygous. The Rhesus genes inherited by the propositi cannot be identified without some risk of ambiguity. It can only be assumed that the child III-7 is illegitimate, since neither of the alleged parents has the B gene.

\section{SUMMARY}

Two Yoruba siblings (a brother and a half-sister) with a rare association of congenital auditory imperception and indifference to pain have been studied and reported. The nature of the defect and the pathophysiology have been discussed with a brief review of the literature. 


\section{REFERENCES}

Alajouanine, Th., and Lhermitte, F. (1965). Acquired aphasia in children. Brain, 88, 653-662.

Allen, I. M. (1952). History of congenital auditory imperception. N.Z. med. J., 51, 239-247.

Baxter, D. W., and Olszewski, J. (1960). Congenital universal insensitivity to pain, Brain, 83, 381-393.

Becak, W., Becak, M. L., and Schmidt, B. J. (1963). Chromosoma trisomy of group 13-15 in 2 cases of generalized congenital analgesia. Lancet, 1, 664-665.

Beecher, H. K. (1959). Measurement of Subjective Responses. Oxford University Press, N.Y.

Berg, I. S. (1961). A case study of developmental auditory imperception, J. Child. Psychol., 2, 86-93.

Boyd, D. A. Jr., and Nie, L. W. (1949). Congenital universal indifference to pain. Arch. Neurol. Psychiat. (Chic.), 61, 402-412.

Brain, Sir W. R. (1961). Neurology of language. Proc. roy. Soc. Med., $54,433-441$.

British Medical Journal (1961). Feeling pain. Brit. med. J., 2, 17631764.

Creak, E. M. (1932). Case of partial deafness simulating congenital auditory imperception. J. Neurol. Psychopath., 13, 133-156.

Critchley, M. (1956). Congenital indifference to pain. Ann. intern. Med., 45, 737-747.

Dancis, J., and Smith, A. A. (1966). Familial dysautonomia. New Engl. J. Med., 274, 207-209.

Davis, D. R. (1957). An Introduction to Psychopathology, p. 161. Oxford University Press, London.

Dearborn, G. V. (1931). A case of congenital general pure anaesthesia. J. nerv. ment. Dis., 75, 612-615.

Eisenson, J. (1963). Disorders of language in children. J. Pediat., 62, 20-24.

Ervin, F. R., and Steinbach, R. A. (1960). Hereditary insensitivity to pain. Trans. Amer. neurol. Ass., 86, 70.

Fanconi, G., and Ferrazzini, F. (1957). Kongenitale analgie. Helv. paediat. Acta., 12, 79-115.

Ford, F. R., and Wilkins, L. (1938). Congenital universal insensitiveness to pain. Bull. Johns Hopk. Hosp., 62, 448-466.

Gerard, R. W. (1960). The physiology of pain. Ann. N.Y. Acad. Sci., 86, 6-12.

Gillespie, J. B., and Perucca, L. G. (1960). Congenital generalized indifference to pain (Congenital analgia). Amer. J. Dis. Child., 100, 124-126.
Gwinn, J. L., Barnes, G. R., Tucker, A. S., and Johnson, C. (1966), Congenital indifference to pain. Ibid., 112, 583-584.

Houwen, H. van der. (1961). A case of neuropathic arthritis caused byD indifference to pain. J. Bone Jt Surg. (Britain), 43-B, 314-317

Kunkle, E. C., and Chapman, W. P. (1942). Insensitivity to pain iro man. Ass. Res. nerv. Dis. Proc., 23, 100-199.

Luzzatto, L., and Allan, N. C. (1965). Different properties of glucose 6-phosphate dehydrogenase from human erythrocytes with normal and abnormal enzymic levels. Biochem. biophys. Res Commun, 21, 547-554.

Magee, K. R., Schneider, S. F., and Rosenzweig, N. (1961). Congenitå indifference to pain. J. nerv. ment. Dis., 132, 249-259.

- (1963). Congenital indifference to pain: an anatomicopatho logical study. Arch. Neurol. (Chic.), 9, 635-640.

Melzack, R., and Wall, P. D. (1965). Pain mechanisms: a new theory:Science, 150, 971-979.

Ogden, T. E., Robert, F., and Carmichael, E. A. (1959). Some sensory syndromes in children-indifference to pain and sensor neuropathy. J. Neurol. Neurosurg. Psychiat., 22, 267-276.

Pavlov, I. P. (1928). Lectures on Conditioned Refiexes. Milford, Oxford

Pinsky, L., and DiGeorge, A. M. (1966). Congenital familial sensory neuropathy with anhidrosis. J. Pediat., 68, 1-13.

Riley, C. M. (1949). Central autonomic dysfunction with defective laciamation. Pediatrics, 3, 468-478.

(1957). Familial dysautonomia. Advanc Pediat., 9, 157-190.

Schilder, P., and Stengel, E. (1931). Asymbolia for pain. Arch. Neurol $\vec{O}$ Psychiat. (Chic.), 25, 598.

Sheridan, M. D. (1961). Disorders of spoken language in youngchildren. Arch. Dis. Childh., 36, 11-16.

Silverman, F. N., and Gilden, J. J. (1959). Congenital insensitivity to pain: a neurological syndrome with bizarre skeletal lesions Radiology, 72, 176-190.

Smithells, R. W. (1967). Familial dysautonomia or the Riley-Dax syndrome. Dev. Med. Child. Neurol., 9, 234-235.

Swanson, A. G., Buchan, G. C., and Alvord, E. C. (1965). Anatomi changes in congenital insensitivity to pain. Arch. Neurol. (ChR.) N $12,12-18$.

Sweet, W. H. (1959). In Handbook of Physiology, Vol., 1, Netiofophysiology. Ed. J. Field, p. 459. Williams and Wilkins, Baltimere-

U.S. Office of International Research (Nutrition Section) (1966) Nutrition Survey. Republic of Nigeria: Preliminary Report $t_{C}$ June, 1966.

Westlake, E. K. (1952). Congenital indifference to pain. Brit. medog. $1,144$. 